\title{
Struktura doczołowych złączy stali ze staliwem zgrzewanych rezystancyjnie
}

\section{Structure of steel and cast steel resistance butt welded joints}

\section{Streszczenie}

W pracy przedstawiono wyniki badań mikrostruktury złączy zgrzewanych stali R260 ze staliwem GX120Mn13 i stalą X10CrNi18-8. Analizowane materiały posiadały charakterystyczne dla siebie rodzaje mikrostruktury. W przypadku złączy zgrzewanych w okolicy linii zgrzania zaobserwowano zjawisko wnikania ciekłego metalu po granicach ziarn, co spowodowane jest niższą temperaturą topnienia materiałów o strukturze austenitycznej w stosunku do stali perlitycznej. Ponadto w tym obszarze zidentyfikowano występującą niejednorodność składu chemicznego materiałów o strukturze austenitycznej związanych z wymieszaniem się materiatów podczas zgrzewania.

Słowa kluczowe: staliwo Hadfielda; stal perlityczna; zgrzewanie rezystancyjne doczołowe; mikrostruktura

\begin{abstract}
The paper presents the results of investigation of the microstructure of welded R260 steel with GX120Mn13 cast steel and $\mathrm{X} 10 \mathrm{CrNi18}-8$ steel. The analyzed materials had characteristic microstructure types. In the case of welded joints next to the fusion line, the phenomenon of liquid metal penetration along grain boundaries was observed, which is caused by the lower melting temperature of austenitic materials in relation to pearlitic steel. In addition, the heterogeneity of the chemical composition of austenitic materials related to the mixing of materials during welding was identified in this area.
\end{abstract}

Keywords: Hadfield cast steel; pearlitic steel; resistance butt welding; microstructure

\section{Wprowadzenie}

Wykonanie połączeń z materiałów posiadających różny skład chemiczny, a także różne właściwości zarówno mechaniczne, jak i elektryczne stwarza problemy w uzyskaniu

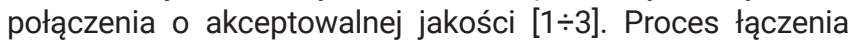
materiałów i wytworzone ciepło powodują powstanie w SWC zmian strukturalnych, które wpływają na właściwości mechaniczne poszczególnych materiałów wchodzących w skład

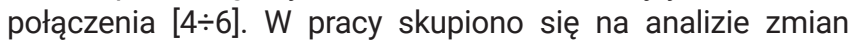
mikrostruktury w obszarze linii zgrzania złączy zgrzewanych rezystancyjnie doczołowo.

\section{Materiał do badań}

Badania prowadzono na złączach zgrzewanych materiałów stosowanych na nawierzchnie szynowe tj. stali szynowej perlitycznej w gatunku R260 (powszechnie stosowanej w kolejnictwie), staliwie w gatunku GX120Mn13 (staliwo Hadfielda, stosowane np. na rozjazdy kolejowe jak i w procesach napawania regeneracyjnego) oraz stali austenitycznej w gatunku X10CrNi18-8 (stosowanej jako przekładka przy łączeniu ze sobą materiałów trudno spajalnych). Skład chemiczny i wybrane właściwości mechaniczne badanych materiałów przedstawiono $\mathrm{w}$ tablicy I.

Tablica I. Skład chemiczny i właściwości mechaniczne badanych stali [7:9]

Table I. Chemical composition and mechanical properties of tested steel $[7 \div 9]$

\begin{tabular}{|c|c|c|c|c|c|c|c|c|c|c|}
\hline \multirow{2}{*}{ Gatunek } & \multicolumn{7}{|c|}{ Skład chemiczny, \% masowe } & \multicolumn{3}{|c|}{ Właściwości mechaniczne } \\
\hline & C & Mn & Si & $\mathrm{Cr}$ & $\mathbf{N i}$ & $\mathbf{P}_{\max }$ & $S_{\max }$ & $\mathbf{R}_{\mathrm{m}}, \mathbf{M P a}$ & $A_{5 \min }, \%$ & $\mathrm{HBW}_{\max }$ \\
\hline $\mathrm{R} 260 *$ & $0,60 \div 0,82$ & $0,65 \div 1,25$ & $0,13 \div 0,60$ & Max 0,15 & - & 0,030 & 0,030 & 880 & 10 & $260 \div 300$ \\
\hline GX120Mn13 & $1,05 \div 1,35$ & $11,00 \div 14,00$ & $0,30 \div 0,90$ & - & - & 0,060 & 0,045 & $800 \div 1100$ & 40 & $190 \div 250$ \\
\hline $\mathrm{X} 10 \mathrm{CrNi18}-8$ & $0,03 \div 0,15$ & $\operatorname{Max} 2,00$ & $\operatorname{Max} 1,0$ & $17,00 \div 19,00$ & $8,0 \div 10,0$ & 0,045 & 0,030 & $600 \div 950$ & 40 & 215 \\
\hline
\end{tabular}

Mgr inż. Zbigniew Żurek - AGH Akademia Górniczo-Hutnicza.

Autor korespondencyjny/Corresponding author: zzurek@agh.edu.pl 


\section{Zakres badań}

Badania mikrostruktury przeprowadzono na próbnych złączach zgrzewanych staliwa GX120Mn13 ze stalą R260 oraz stali X10CrNi18-8 ze stalą R260. Procesowi zgrzewania doczołowego zwarciowego na zgrzewarce ASPA typ ZDZ 7 poddano pręty o wymiarach poprzecznych $10 \times 10 \mathrm{~mm}$ i długości $55 \mathrm{~mm}$. Próbki montowano w uchwytach zaciskowych z zachowaniem symetryczności połączenia względem uchwytów zgrzewarki stosując zmienne parametry zgrzewania, zamieszczone w tablicy II.

Tablica II. Parametry procesu zgrzewania

Table II. Resistant butt-welding process parameters

\begin{tabular}{|c|c|}
\hline Parametr & Zakres \\
\hline Natężenie prądu I & $113 \div 148 \mathrm{~A}$ \\
\hline Czas przepływu prądu t & $2,0 \div 2,6 \mathrm{~s}$ \\
\hline Droga spęczania a & $2 \div 4 \mathrm{~mm}$ \\
\hline Odległość między szczękami b & $15 \mathrm{~mm}$ \\
\hline
\end{tabular}

Badania mikroskopowe przeprowadzono z uwzględnieniem zaleceń PN-EN ISO 17639. Próbki szlifowano na papierach ściernych o zmniejszającej się gradacji (do 1500), zmieniając za każdym razem kierunek szlifowania o $90^{\circ}$, a następnie próbki polerowano mechanicznie w wodnej zawiesinie $\mathrm{Al}_{2} \mathrm{O}_{3}$. Tak wypolerowane próbki trawiono elektrolitycznie w $10 \%$ wodnym roztworze $\mathrm{CrO} 3 \mathrm{w}$ przypadku staliw GX120Mn13 i X10CrNi18-8 oraz 4\% nitalem o składzie $4 \% \mathrm{HNO}_{3}+96 \% \mathrm{C}_{2} \mathrm{H}_{5} \mathrm{OH}$ w przypadku stali R260. Obserwacji dokonano za pomocą mikroskopu świetlnego oraz skaningowego mikroskopu elektronowego wyposażonego w analizator EDS.

\section{Wyniki badań}

Mikrostrukturę materiałów stosowanych do wykonania złączy zgrzewanych przedstawiono na rysunku 1. Stal R260 posiada mikrostrukturę perlityczną z niewielką ilością ferrytu na granicach ziarn. Staliwo GX120Mn13 charakteryzuje się zbliźniaczoną mikrostrukturą austenityczną, a stal X10CrNi18-10 mikrostrukturą austenityczną z ferrytem $\delta$ ułożonym pasmowo w kierunku przeróbki plastycznej.

Mikrostrukturę złącza zgrzewanego staliwa GX120Mn13 ze stalą R260 przedstawiono na rysunku 2. Przy linii zgrzania po stronie stali R260 widoczne są efekty nadtopienia się granic ziaren. Temperatura solidus w przypadku tych materiałów jest zbliżona, niemniej jednak dla staliwa GX120Mn13 jest nieco niższa. Lokalne niejednorodności składu chemicznego powodują powstawanie nadtopień i wnikanie ciekłego staliwa GX120Mn13 w głąb stali R260 po granicach ziarn, co jest wyraźnie widoczne na rysunku $2 b$. Ciemniejsze pasmo w jasnym obszarze austenitu stanowi austenit powstały w wyniku zmiany składu chemicznego przez wymieszanie się materiałów podczas zgrzewania (rys. 2b). Przeprowadzona analiza EDS na skaningowym mikroskopie elektronowym potwierdza znaczne wzbogacenie $w$ mangan jasno trawiących się obszarów (rys. 2c, punkty 1 i 2). Wysoka temperatura w pobliżu linii zgrzania prowadzi do utworzenia austenitu, który w wyniku chłodzenia ulega przemianie w martenzyt i/ lub bainit, o czym świadczy płytkowy charakter mikrostruktury (rys. 2b). W obszarach tych (punkt 3 na rys. 2c) skład chemiczny stali R260 jest zachowany. W dalszej odległości od linii zgrzania obserwuje się typowe dla SWC obszary przemian fazowych i wywołanych nimi zmiany mikrostruktury.
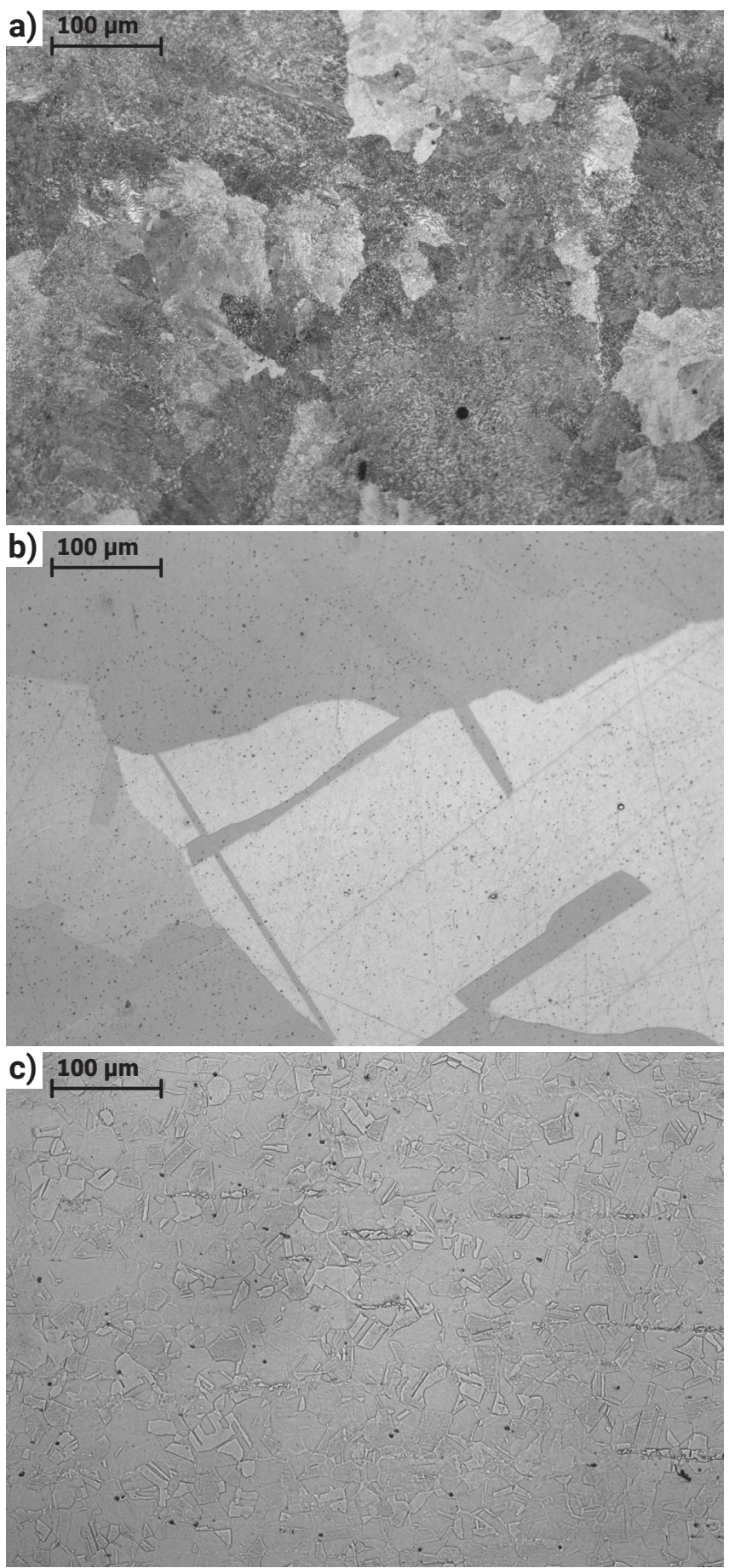

Rys. 1. Mikrostruktura: a) stali R260, b) staliwa GX120Mn13, c) stali X10CrNi18-8

Fig. 1. Microstructure: a) R260 steel, b) GX120Mn13 cast steel, c) $\mathrm{X} 10 \mathrm{CrNi18}-8$ steel

Mikrostrukturę złącza stali X10CrNi18-8 i stali R260 przedstawiono na rysunku 3. W tym przypadku wymieszanie materiałów zaszło w znacznie większym stopniu. Po stronie stali R260 strefa ta sięga około $500 \mu \mathrm{m}$. Proces dotyczy nie tylko penetracji cieczy stali austenitycznej X10CrNi18-8 po granicach ziarn stali perlitycznej (granicach ziarn byłego austenitu), ale również procesu dyfuzji zachodzącego wewnątrz ziarn (rys. 3b). W dalszej odległości od linii zgrzania obserwuje się typowe dla SWC obszary przemian fazowych i wywołanych nimi zmiany mikrostruktury. Nawet w dość znacznej odległości od linii zgrzania obserwuje się wzbogacenie granic ziarn byłego austenitu w stali R260 w chrom i nikiel (punkt 1, rys. 3c). Również wnętrza ziarn wykazują nieznaczny wzrost koncentracji tych pierwiastków wskutek zachodzenia procesu dyfuzji (punkt 2, rys. 3c). 

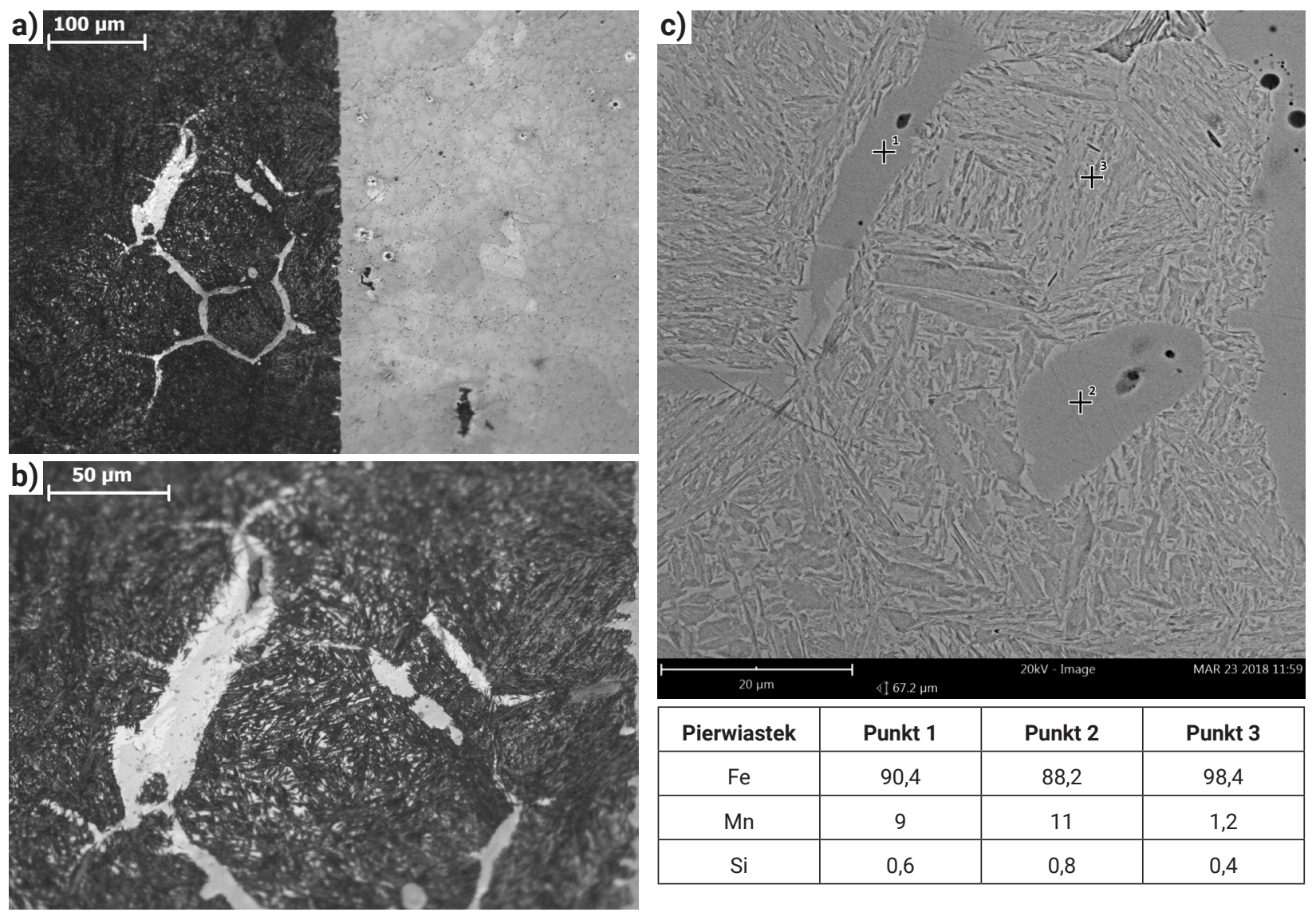

\begin{tabular}{|c|c|c|c|}
\hline Pierwiastek & Punkt 1 & Punkt 2 & Punkt 3 \\
\hline $\mathrm{Fe}$ & 90,4 & 88,2 & 98,4 \\
\hline $\mathrm{Mn}$ & 9 & 11 & 1,2 \\
\hline $\mathrm{Si}$ & 0,6 & 0,8 & 0,4 \\
\hline
\end{tabular}

Rys. 2. Mikrostruktura złącza zgrzewanego staliwa GX120Mn13 ze stalą R260 w okolicy linii zgrzania: a) obszar przy linii zgrzania, b) struktura stali perlitycznej z widocznym staliwem wnikającym po granicach ziarn, c) analiza składu chemicznego w obszarze penetracji przez staliwo Fig. 2. Microstructure of resistant butt-welded GX120Mn13 cast steel with R260 steel in the area next to fusion line: a) fusion line, b) liquid metal penetration along grain boundaries in pearlitic steel, c) SEM analysis in liquid metal penetration area
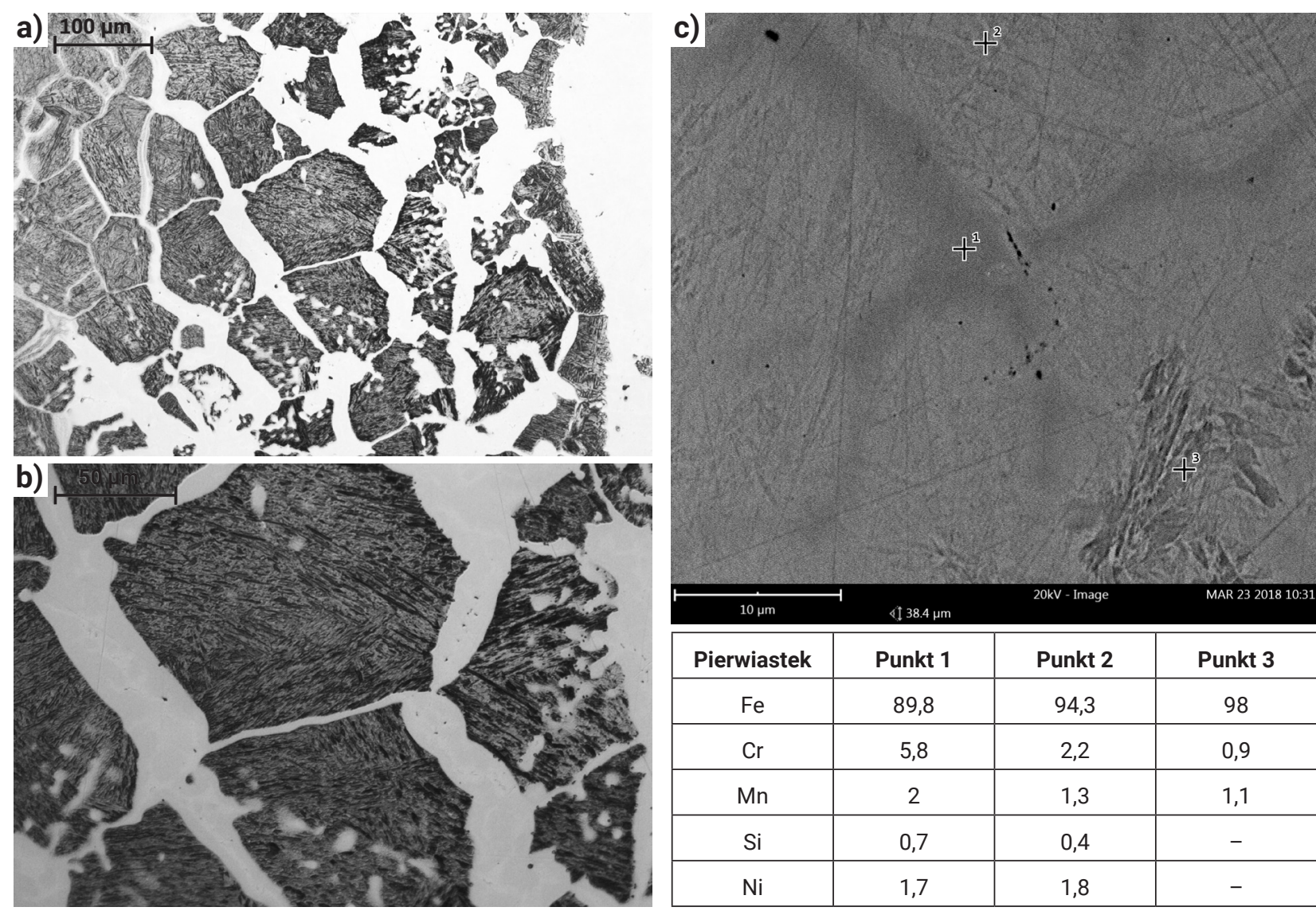

\begin{tabular}{|c|c|c|c|}
\hline Pierwiastek & Punkt 1 & Punkt 2 & Punkt 3 \\
\hline $\mathrm{Fe}$ & 89,8 & 94,3 & 98 \\
\hline $\mathrm{Cr}$ & 5,8 & 2,2 & 0,9 \\
\hline $\mathrm{Mn}$ & 2 & 1,3 & 1,1 \\
\hline $\mathrm{Si}$ & 0,7 & 0,4 & - \\
\hline $\mathrm{Ni}$ & 1,7 & 1,8 & - \\
\hline
\end{tabular}

Rys. 3. Mikrostruktura złącza zgrzewanego stali X10CrNi18-8 ze stalą R260 w okolicy linii zgrzania: a) obszar przy linii zgrzania, b) struktura stali perlitycznej z widoczną stalą austenityczną wnikającą po granicach ziarn, c) analiza składu chemicznego w obszarze penetracji przez stal austenityczną

Fig. 3. Microstructure of resistant butt-welded X10CrNi18-8 steel with R260 steel in the area next to fusion line: a) fusion line, b) liquid metal penetration along grain boundaries in pearlitic steel, c) SEM analysis in liquid metal penetration area 


\section{Podsumowanie}

Łączenie materiałów różnorodnych nastręcza wiele problemów związanych zarówno z brakiem stabilności mikrostruktury, nie tylko w czasie samego procesu, ale również podczas pracy połączeń. Szczególnie niebezpieczne jest łączenie materiałów wykazujących różną aktywność węgla nawet przy tej samej jego zawartości w materiałach łączonych. Prowadzi to do znaczących niejednorodności strukturalnych obniżających właściwości mechaniczne połączenia.

Badania złączy próbnych materiałów stosowanych na szyny i rozjazdy kolejowe wykazały, że w linii zgrzania obserwuje się zarówno nadtopienie materiałów, jak i w niewielkim stopniu ich wymieszanie. Zmiany mikrostruktury w SWC są znaczące i wynikają z charakteru procesu oraz składu chemicznego łączonych materiałów. W stali R260 obserwuje się w pobliżu linii zgrzania tworzenie martenzytu i/lub bainitu, którego udział maleje w miarę przesuwania się w kierunku materiału rodzimego. Obserwacje mikroskopowe ujawniły w okolicy linii zgrzania wnikanie ciekłego staliwa GX120Mn13 oraz ciekłej stali X10CrNi18-8 po granicach ziarn stali R260.

\section{Literatura}

[1] Nikitin A. S.: Flash welding Hadfield steel to rail steel, Welding International, vol. 15 (3), 2001, pp. 217-219.

[2] Zhang F., Lv B., Hu B., Li Y.: Flash butt welding of high manganese steel crossing and carbon steel rail, Materials Science and Engineering: $A$, vol. 454-455, 2007, pp. 288-292.

[3] Nikulina A. A., Bataev A. A., Smirnov A. I., Popelyukh A. I., Burov V. G., Veselov S. V.: Microstructure and fracture behaviour of flash butt welds between dissimilar steels, Science and Technology of Welding and Joining, vol. 20 (2), 2015, pp. 138-144.

[4] Kuchuk-Yatsenko S.I., Didkovsky A.V., Shvets V.I., Antipin E.V., Wojtas P., Kozłowski A.: Flash-butt welding of high-strength rails, Mining - Informatics, Automation and Electrical Engineering, vol. 528 (4), 2016, pp. 40-49.

[5] Porcaro R. R., Paes de Lima D. A., Lúcio de Faria G., Godefroid L. B., Cândido L. C.: Microestrutura e Propriedades Mecânicas de um Aço para Trilhos Ferroviários Soldado por Centelhamento, Soldagem \& Inspeção, vol. 22 (1), 2017, pp. 59-71.

[6] Mansouri H., Monshi A.: Microstructure and residual stress variations in weld zone of flash-butt welded railroads, Science and Technology of WeIding and Joining, vol. 9 (3), 2004, pp. 237-245.

[7] PN-EN 13674-1+A1:2017-07 - Kolejnictwo - Tor - Szyna - Część 1: Szyny kolejowe Vignole'a o masie $46 \mathrm{~kg} / \mathrm{m}$ i większej.

[8] ISO 13521:2015 - Austenitic Manganese Steel Castings.

[9] PN-EN 10088-1:2014-12 - Stale odporne na korozję - Część 1: Wykaz stali odpornych na korozję. 